\title{
Development of DAYSAM: An Educational Smart Phone Game for Preschoolers to Increase Awareness of Renewable Energy
}

\author{
Tamer Khatib ${ }^{1, *(D)}$, Haneen Alwaneh ${ }^{2}$, Wajdi Mabroukeh ${ }^{2}$, Yassmin Abu-Ghalion ${ }^{1}$, Fatima Abu-Gadi ${ }^{3}$, \\ Aliaa Assali ${ }^{4}$, Wilfried Elmenreich ${ }^{5}$ id and Muna Zarour ${ }^{6}$
}

1 Department of Energy Engineering and Environment, An-Najah National University, Nablus 97300, Palestine; y.abughalion@stu.najah.edu

2 Department of Computer Engineering, An-Najah National University, Nablus 97300, Palestine; h.alwaneh@stu.najah.edu (H.A.); w.mabroukeh@stu.najah.edu (W.M.)

3 An-Najah Child Institute, An-Najah National University, Nablus 97300, Palestine; f.abugadi@najah.edu

4 Faculty of Educational Sciences and Teachers' Training, An-Najah National University, Nablus 97300, Palestine; Alia_71@najah.edu

5 Institute of Networked and Embedded Systems, University of Klagenfurt, 9020 Klagenfurt, Austria; wilfried.elmenreich@aau.at

6 Department of Industrial Engineering, An-Najah National University, Nablus 97300, Palestine; m.abuzaror@stu.najah.edu

* Correspondence: t.khatib@najah.edu

check for updates

Citation: Khatib, T.; Alwaneh, H.; Mabroukeh, W.; Abu-Ghalion, Y.; Abu-Gadi, F.; Assali, A.; Elmenreich, W.; Zarour, M. Development of DAYSAM: An Educational Smart Phone Game for Preschoolers to Increase Awareness of Renewable Energy. Sustainability 2021, 13, 433. https://doi.org/10.3390/su13010433

Received: 7 December 2020 Accepted: 29 December 2020 Published: 5 January 2021

Publisher's Note: MDPI stays neutral with regard to jurisdictional clai$\mathrm{ms}$ in published maps and institutional affiliations.

Copyright: (C) 2021 by the authors. Licensee MDPI, Basel, Switzerland. This article is an open access article distributed under the terms and conditions of the Creative Commons Attribution (CC BY) license (https:// creativecommons.org/licenses/by/ $4.0 /)$.

\begin{abstract}
This paper presents a smartphone application game that aims to increase the awareness of preschoolers on renewable energy. The age of the selected preschoolers is in the range of 4-6 years. The game is called DAYSAM, and it aims to increase awareness regarding photovoltaic arrays, wind turbines, mini-hydropower stations, energy efficiency, and risks that polar bears are facing. The game provides two superior features compared to other available games in Arabic language, targeting the same age group. Preschoolers from An-Najah Child Institute are selected to play this game to investigate the impact of this game. The preschoolers' awareness is tested before and after playing the game using coloring sheets in an unsupervised coloring process. The results show that the proposed game has increased preschooler's awareness of renewable energy. Before playing the game, none of the preschoolers recognized images like the photovoltaic array or the wind turbine. After playing the game the preschoolers recognized these devices in different situations and shapes. This indicates that such a game can be used as a fun and educational tool in nurseries that have Arabic communication medium to increase awareness of renewable energy.
\end{abstract}

Keywords: renewable energy; awareness; preschoolers; game; Palestine

\section{Introduction}

The failure of renewable energy implementation is often connected to low public awareness, policy failures, and market characterization. Among other factors, the public may induce behavioral barriers for renewable energy dissemination [1]. These behavioral barriers can be defined as negative decisions of the end-user regarding renewable energy. Therefore, a reason can be an end-user's limited recognition of renewable energy, while better awareness of renewable energy leads to a positive attitude toward these technologies [2]. According to [2], Palestinian youth show limited awareness of renewable energy for many reasons, including insufficient inclusion of renewable energy information in school and academic curricula. Thus, it is essential to intervene and inform at the early learning stages in kindergartens. Many learning methods can drive children's attention toward a specific aspect and, consequently, increase awareness. Among these methods are computer games and smartphone applications [3,4].

According to [5], computer games for learning aim at promoting academic learning, including content knowledge in academic subject areas and cognitive skills that support 
academic learning. Social experiments show that computer games for learning help children develop a more positive attitude towards useful things than their formal learning in school [6-10]. Therefore, a computer game or a smartphone application game that deals with renewable energy with content suitable for children may increase awareness of the topic among these children.

In general, there are some renewable energy and environmental games that can be played either on a computer or smartphones. In this paper, a review of these games is done considering them as benchmarks to the proposed DAYSAM to show the importance of this smartphone game and evaluate its features compared to other related games. One of the available games for renewable energy awareness is EnerCities [11]. EnerCities is an online eLearning game for children to experience energy-related implications. The game's goal is to create and expand virtual cities dealing with pollution, energy shortages, usage of renewable energy, etc. The game is web-based and supports several languages, but not Arabic. The game has an elegant appearance, and it makes students aware of the role and implications of energy in society and energy saving on household level. Specific research funded by the EU [11] indicated higher levels of attitudes (and behavior intentions) of EnerCities players regarding energy saving at home in comparison with the control group (non-EnerCities players). EnerCities targets children with age above six and does not support Arabic language. Other than in the game DAYSAM, the game's focus is energy in general and not renewable energy. Another available game is Olliesworld [12] which is distributed via a website for children providing fun and entertaining ways to learn how to reduce, reuse, recycle and rethink in the areas of waste, water, energy. Olliesworld's educational methods focus on games such as crossword games, energy-saving games, light-saving games, etc. Another web-based gamified approach is Saveonenergy [13]. Saveonenergy is based upon a website containing facts about electricity and giving some tips that help the player use energy wisely. Related information appears as text-embedded pictures, including biographies of scientists and a list of renewable and non-renewable energies. WindFall [14] is a challenging, educational, and thought-provoking environmental science and renewable energy tycoon game. The player has to build sufficient wind turbines to power a small town and profit without disturbing the residents or sullying the landscape. This game is highly interactive and stimulates sustainable energy management simulation activities for children and teens but not preschoolers.

Most of the games, as mentioned above, are in general targeting children who are older than six. Additionally, some of them can only be played using a website browser, which, given the increasing preference for smartphone apps among young players [15], limits the game's impact. Despite some of the games being multilingual, none of the listed games support the Arabic language, which is the commonly spoken language in the area where preschoolers' experiments took place. It is also the fifth most spoken language, according to the United Nations official languages. Finally, only one of these games has been investigated in terms of the impact on players considering the level of awareness of renewable energy. Thus, in this research, DAYSAM, the baby polar bear's Arabic name, is proposed. DAYSAM is a smartphone application game that aims to help preschoolers become aware of renewable energy and energy efficiency. DAYSAM is characterized by its Arabic content suitable for children aged 4-6 years. The game has audio support to clarify the game's concepts, help the child choose the appropriate step, and eases interaction with the game. DAYSAM delivers different concepts, such as learning how to use renewable energy tools and saving energy in daily life. This game also helps in empowering planning and problem-solving skills at an early stage.

\section{Hypothesis and Pretesting}

In general, it is assumed in this research that the preschoolers' awareness in Palestine of renewable energy and energy efficiency is low. The level of preschoolers' awareness of renewable energy can be predicted based on two indicators. One indication for this is the lack of renewable energy, energy efficiency, and environmental topics in the preschoolers' 
adapted curriculum. In addition, a study on the awareness of the Palestinian youth has been performed as previous work to this paper [2]. Results indicate that the limited awareness of the Palestinian youth needs to be addressed in many ways starting from primary education. In this previous research, a pre-testing tool was developed to measure the level of awareness. A coloring sheet, as shown in Figure 1, was devised with features close to the later developed game features. This coloring sheet was then distributed to five preschoolers (the total number of preschoolers is 40) from An-Najah Child Institute's nursery. The preschoolers were asked to color this sheet three times for two weeks.

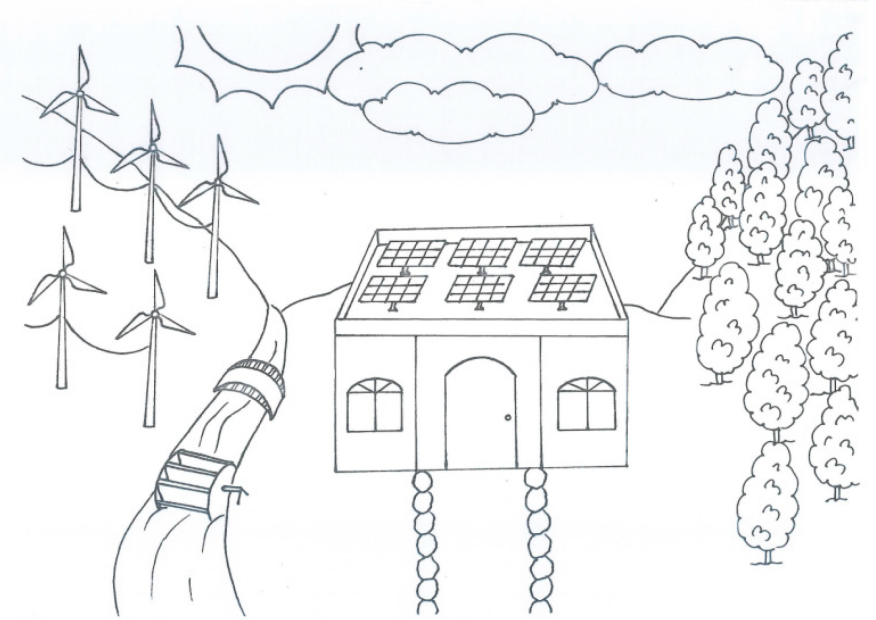

Figure 1. Pre-testing coloring sheet.

One month after playing the game, a similar coloring sheet was distributed to the same preschoolers, and they were asked to color it three times over two weeks. Figure 2 shows the testing coloring sheet.

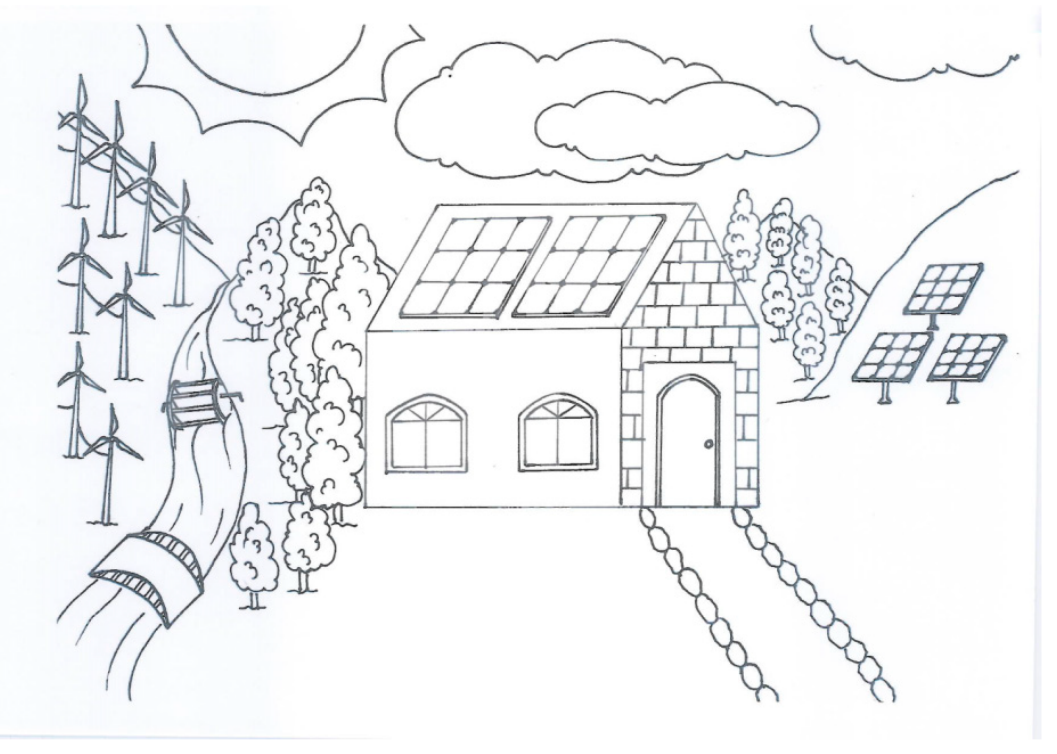

Figure 2. Testing coloring sheet.

This methodology is proposed to demonstrate the impact on preschoolers' awareness of renewable energy concepts after playing the game. It is worth mentioning that the coloring was found suitable to test preschoolers' awareness with minimum intervention since the coloring process is done without direct supervision. 
This pre-testing sheet supports addressing the following research questions: "do preschoolers recognize solar panels and their color?", "do preschoolers recognize wind turbines and their color?", "do preschoolers recognize hydropower wheel and its color?", "do preschoolers recognize ambient environment components such as Sun, trees and clouds and their colors?". Here the previous pretesting process is not used fully to evaluate the assumed research questions and hypotheses. This pretesting process is mainly aimed to test the validity of the game by minimum number of preschoolers in order to evaluate the use and the convenience of the proposed game by the selected preschoolers. The initial validation of this process is done by evaluating the coloring performance of the preschoolers and by watching their behavior while playing the game so as to consider any feedback in the long testing process. The feedback is mainly obtained by analyzing the coloring sheets and a report from preschoolers' supervisor. The main focus of this pretesting is to test the physical components of the game and the interaction of the preschoolers while playing it. Meanwhile, the long testing process is dedicated to validating this study's questions and hypotheses.

Table 1 lists five main research questions that were identified for testing the awareness of preschoolers of renewable energy as well as the impact of the developed game.

Table 1. Adapted Research questions.

\begin{tabular}{|c|c|c|}
\hline Q & Research Question & Testing Sheet \\
\hline 1 & > Do preschoolers in Palestine recognize the standalone solar cell and color it blue? & $1,2 \& 5$ \\
\hline 2 & > Do preschoolers in Palestine recognize the rooftop solar cell and color it blue? & $1 \& 2$ \\
\hline 3 & $>$ Do preschoolers in Palestine recognize the sun and color it yellow? & $1 \& 5$ \\
\hline 4 & > Do preschoolers in Palestine recognize the earth and color it blue and green? & 5 \\
\hline 5 & $>$ Do preschoolers in Palestine recognize the wind turbine and color it white (no color)? & $3 \& 4$ \\
\hline 6 & $>$ Do preschoolers in Palestine recognize the lighting lamp and color it yellow? & 4 \\
\hline
\end{tabular}

As for the testing tool, a coloring book that contains many coloring sheets, including the sheets shown in Figure 3 was used. These coloring sheets are used as a longterm testing tool in this research. The coloring booklet contains many coloring sheets for many things, such as sports activities, animals, and specific coloring sheets shown in Figure 3. The aim of this is to put the preschooler in a free environment without any pressure to focus on a specific topic.
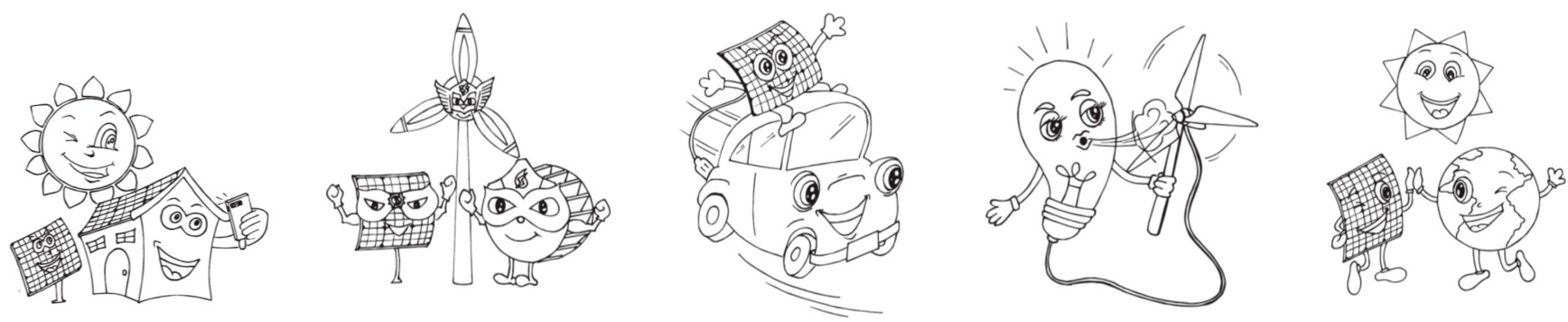

Figure 3. Testing coloring sheets that are used for long term testing.

In this research, it is assumed that an unconscious decision drives the role of choosing colors by preschoolers. When the preschooler is familiar with an object such as "Superman" or "Hulk", the typical reaction is to choose blue and red colors for Superman and green color for Hulk as he the preschooler is familiar with these characters. Otherwise, the preschooler may choose a random color to color these objects. Here, being familiar with an object is tested by evaluating familiarity with the object's characteristics. A similar concept is used in packaging products in boxes with colors assigned to a specific attribute [16]. For example, if a preschooler is familiar with a polycrystalline photovoltaic panel, they would likely choose a blue color for coloring it. 


\section{DAYSAM Development Process}

In this section, game concept, development process, and requirements are described to show the full process of DAYSAM development and its basis.

\subsection{DAYSAM Overview and Requirement}

In general, the main scene for this game is a house in the woods that is set up as a smart microgrid [17] with its own local energy production units. In the house's garden, a diesel engine is emitting smoke polluting the environment while powering the house. Here, the main aim is to replace this diesel generator with renewable energy sources. The available renewable energy sources are photovoltaic array, wind turbine, and minihydropower station. First, the player should do two main things to reduce the house's unneeded lights to save energy. Then, the player should choose the appropriate renewable energy source based on the ambient weather. In this game, three main ambient weather cases are referred to as "environmental moods". These moods are sunny, windy, and rainy. The environmental mood is randomized every time the game starts to present a realistic game experience. Meanwhile, scene lights, background sounds, and models are also changed to match the environmental mood.

The user can enter the house by clicking on the door; then, six different house rooms are shown on the screen. There is a light in each room that can have two different states, which are ON and OFF. Each room's light is controlled by a random number generated every time the game starts representing the number of rooms. This random number also controls the engine smoke size, whereas the larger the number of lighted rooms, the bigger the engine smoke size. After that, the user can enter any room by clicking on it; then, the room is zoomed in. The user can also zoom out the room and go back to the view of all rooms by clicking anywhere outside the zoomed-in room. In this game level, all rooms are vacant, and thus, the right action to save energy is to turn all the lights off.

To win the game, the player has to stop the diesel engine from emitting smoke, which is achieved by minimizing energy consumption. A timer is provided in this game, represented by a polar bear standing up on a piece of ice. The more time it takes the player to shut down the diesel generator, the smaller the ice piece gets, which visually upsets the polar bear. When the ice piece is completely melted, time is over, and then the player loses this round. Figure 4 shows the initial drawing of the main screen of DAYSAM.

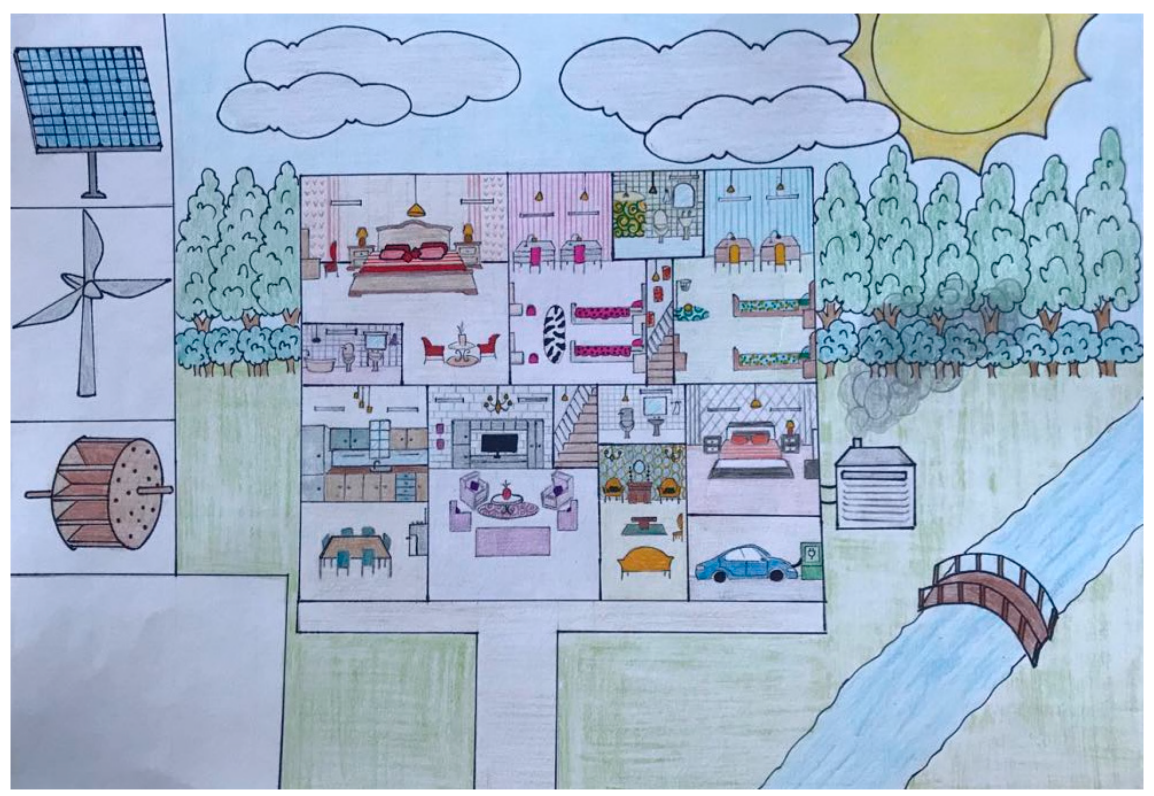

Figure 4. Initial drawing of DAYSAM's main page. 
In general, there are several tasks that the user must finish to accomplish the goal of the game as follows,

- With every room light the player turns off; they get an extra coin

- With every light the player turns off, the engine smoke size decreases

- If the user turns off all the rooms, she/he will earn six coins

- Six coins are needed to buy a renewable energy tool

- The player has to buy the correct tool in order to turn off the diesel engine and win the game

- The correct tool is the one that can be utilized best in the current environmental setting. For example, the right tool for the windy environment is the wind turbine

Based on this overview, DAYSAM requirements can be listed as below,

- DAYSAM should have three different environments, sunny, windy, and rainy. Therefore, for each mood, the way the sky looks should be changed accordingly.

- The game level should be different every time the game starts anew.

- A different background sound should be played, matching each environmental mood.

- There is a river next to the house for hydro energy use. Thus, for the rainy environment, this river should be moving fast.

- The user should be able to click on the house door and move inside the house. When the user enters the house, six different rooms are shown, bedroom, girls' room, boys' room, kitchen, bathroom, and a living room.

- Every room should be clickable and provide some interaction.

- Clicking a room should zoom out the specific room, hiding the other rooms.

- Clicking on the screen outside the displayed room returns to the view with all of the rooms shown.

- Every room should have a clickable light.

- Clicking on the room light toggles it on/off.

- Clicking on the light is only enabled when the room is zoomed in

- The number of lit rooms is different each time the game starts.

- An engine is emitting smoke and stopping the smoking generator is the main challenge of the game.

- Turning off a room light will decrease the power consumption (and smoke amount). Turning a light on will increase power consumption and smoke amount.

- The number of lit rooms initially controls the smoke amount.

- A coin is given to the player each time she/he turns off the light.

- The number of possessed coins is displayed on top of the screen.

- When the user earns a coin, coins splash on the screen.

- On the side of the screen, the available renewable energy tools are shown.

- The player can buy any of the tools if she/he owns sufficient coins for its value. The value of the tool is earned by turning off all of the rooms.

- The player should be able to drag the tool and drop it anywhere on the ground. The hydropower station needs to be placed on the river.

- If the player places the wrong tool, it is returned, and the user should be able to buy another one.

- If the player buys the right tool and places it in the right place, engine smoke stops.

- When the user places the right tool, an indication should be used to show that the tool is working.

- When the engine smoke size stops, the player wins the round, and she/he should be able to start another round.

- A timer represented by a polar bear standing up on a piece of ice should be shown. As time passes, the ice sheet is shrinking, indicating a melting process. When the ice sheet is completely melted, time is over then the player loses this round.

Figures 5 and 6 show the development diagrams of DAYSAM as sequence diagram and a use case diagram. 


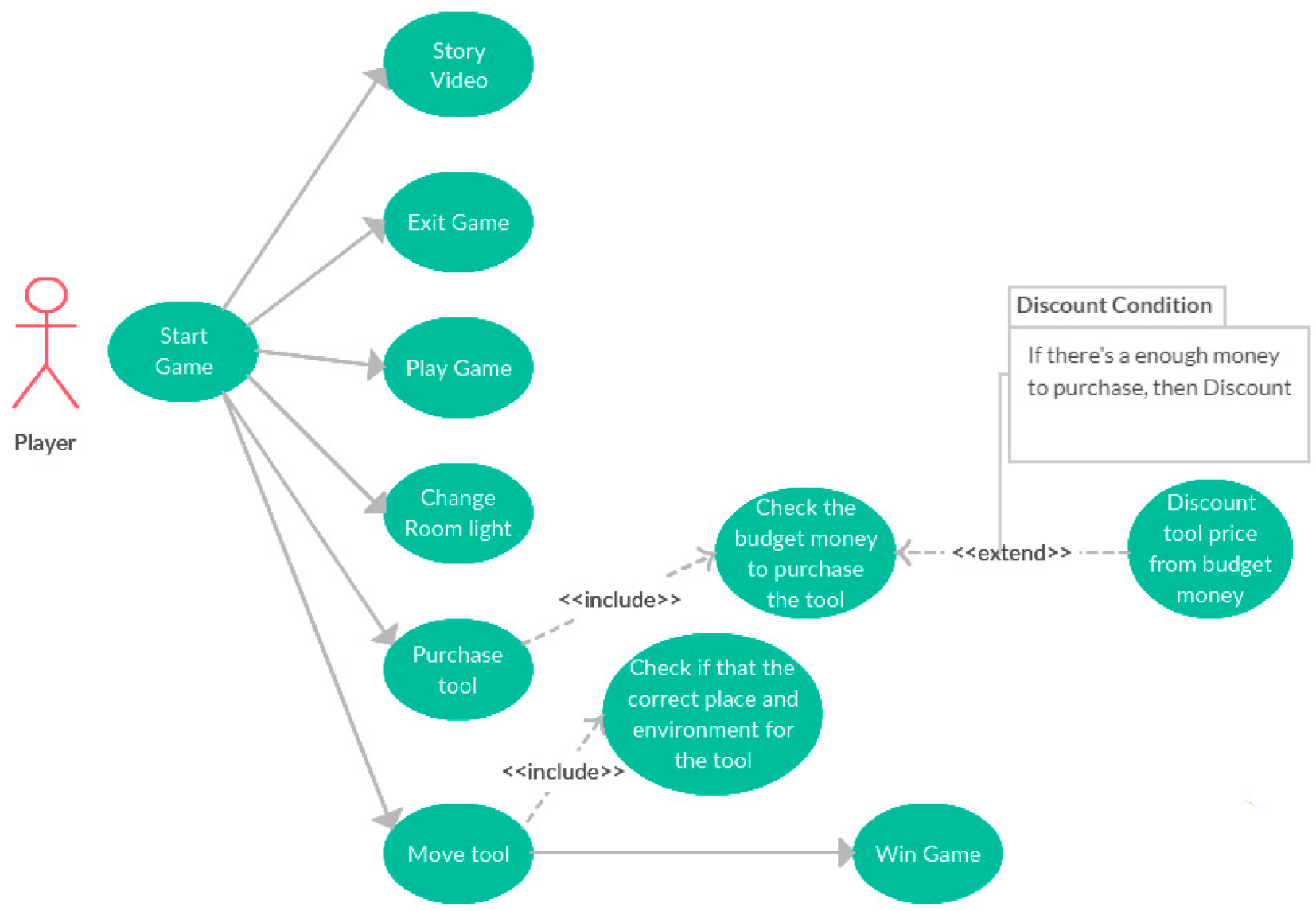

Figure 5. DAYSAM's use case diagram.

\subsection{DAYSAM Game Models Development}

The choice of the game engine was one of the most important decisions in developing DAYSAM. Different engines can be used for game development such as, for example, Unity, Unreal, and CryEngine. In this research, Unity was chosen as a game engine for its great user experience, cross-platform integration, detailed documentation, and a big community for game developers. Unity's MonoDevelop and Microsoft Visual studio are the IDEs that were used for coding. The main programming language that is used for developing this game is C\#. Some game models are designed internally in Unity, although most of the game's models were designed in external editors SketchUp and Blender. Figure 7 shows the main models used for DAYSAM.

Figure 7a shows the model representing the user's house shown on the game start page. Figure $7 \mathrm{~b}$ shows a collection of room models used. Figure $6 \mathrm{c}$ shows the diesel generator engine that needs to be stopped in order to win the game. Figure $7 \mathrm{~d}$ shows the sun and the clouds that are used in the windy environmental mood. Accordingly, Figure 7e shows the sun and clouds that are used in the sunny environmental mood. Figure $7 \mathrm{f}-\mathrm{h}$ show photovoltaic, wind turbine, and water wheel models, which represent the tools used for converting different kinds of energy into electricity to replace the engine and win the game. Figure 7i-k show the river's models with different wave speeds, trees, and ground. The ground model represents the ground outside the house. 


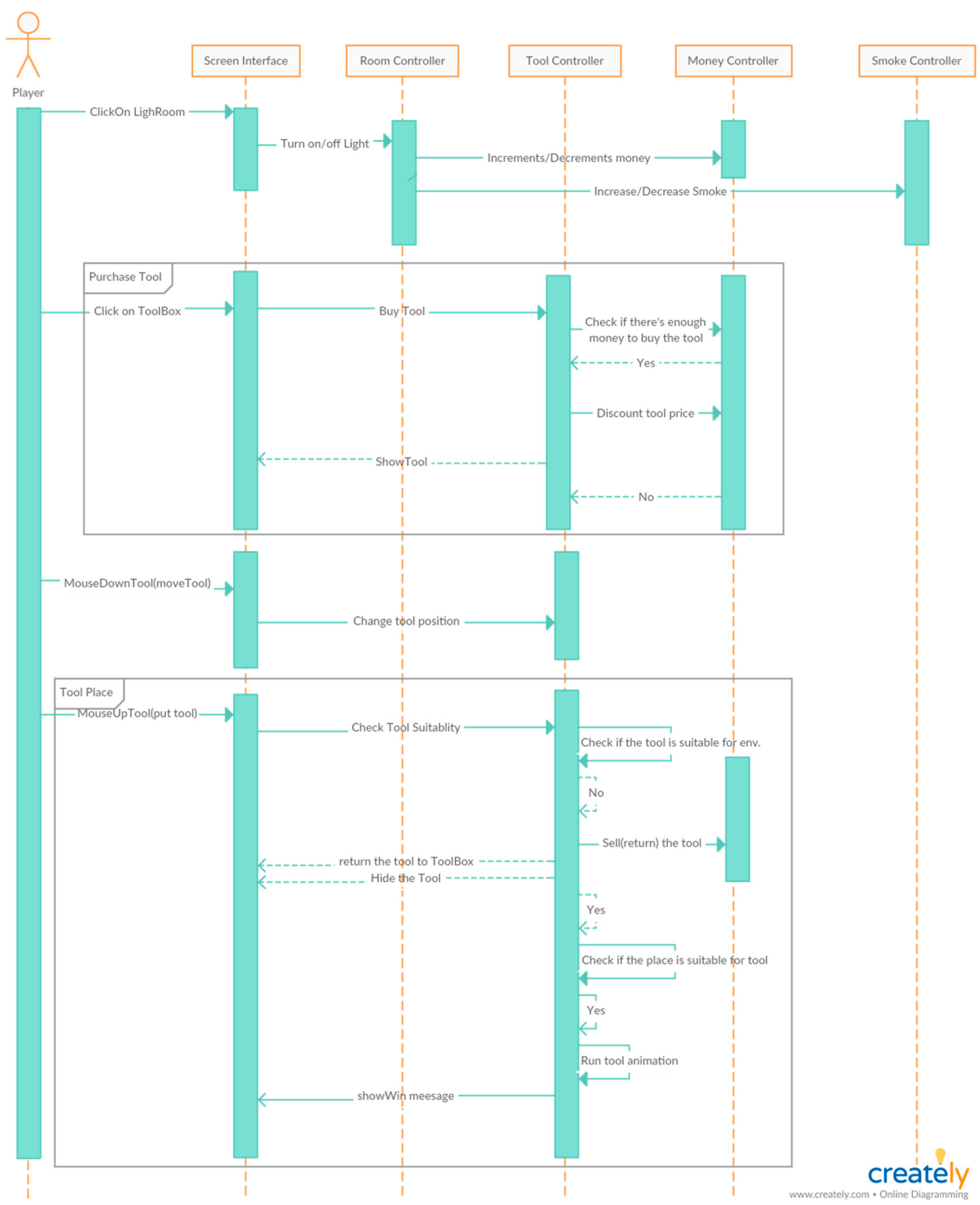

Figure 6. DAYSAM Sequence diagram.

\subsection{DAYSAM's Animations}

Creating an appealing experience and well recognizable objects is on top of the nonfunctional requirements for this game. Many elements are animated, such as clouds, sun, trees, wind turbines, and the mini-hydropower station's water wheel.

Clouds animation is a looping animation that moves clouds across the screen with a total duration of $32 \mathrm{~s}$. This animation is played when the environment's mood is windy. It is created using a Unity animator using game object transform's position around the $x$-axis. Meanwhile, Sun animation is a looping animation responsible for animating the sun rays around the sun. This animation is played in a sunny environmental mood. Sun animation is achieved by using Transform. Rotate Around function. This function is responsible for rotating game objects around an axis passing through a point at a specific angle. 


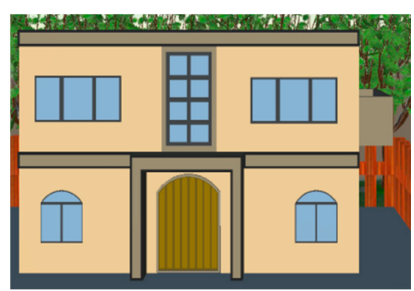

(a)

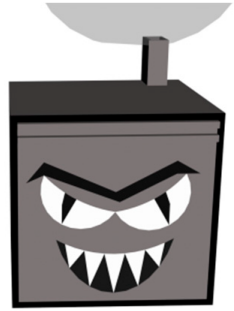

(c)

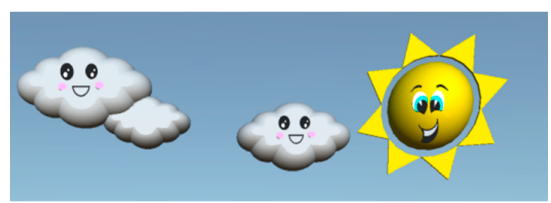

(e)

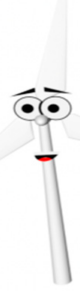

(g)

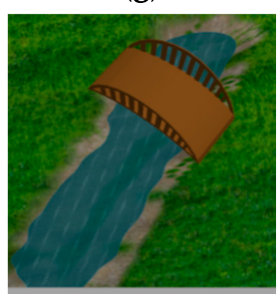

(i)

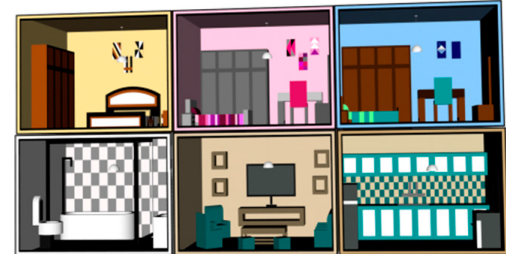

(b)
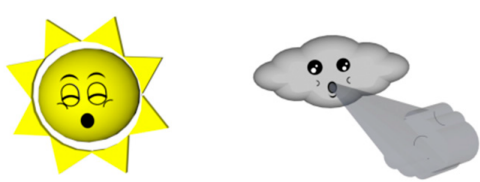

(d)

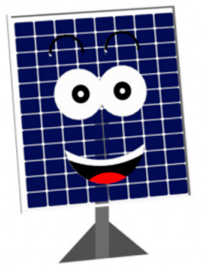

(f)

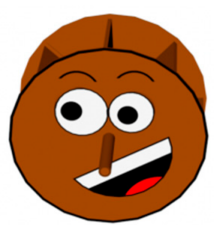

(h)

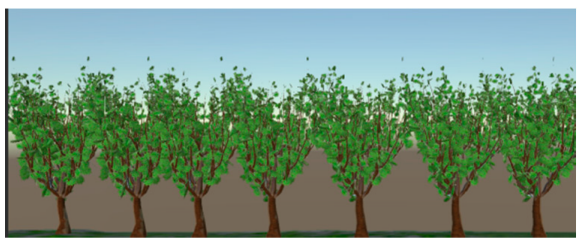

(j)

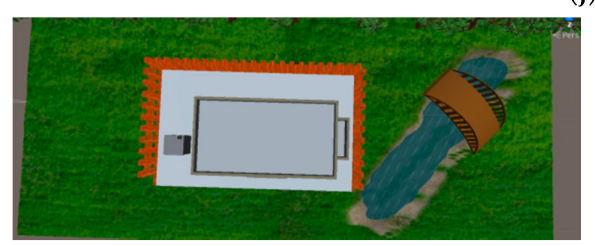

(k)

Figure 7. DAYSAM developed models.

As for trees animation, it is played in the windy environmental mood; Unity's wind zone is used to create this animation. Wind zones allow terrain trees to animate in a realistic fashion, whereas wind creates pulses creating natural patterns affecting trees movement. The directional mode is chosen for the wind zone to affect the whole terrain at once. Both of 
the zone's properties, main and turbulence, which control the wind strength with a random variation, are set to a value of 3 . Pulse magnitude, which controlled the strength of the wind pulses, is set to a value of 0.5 . The wind pulses' time interval is set to $1 \mathrm{~s}$, which is controlled by the pulse frequency property.

In the meanwhile, wind turbine animation is a looping animation created for rotating wind turbine blades. This animation is played when the environment is windy, and the player places the turbine on the ground after buying it from the tools inventory. Again, Transform. Rotate Around function is used for creating this animation. This animation creates a circular animation for the blades in 50 degrees/second. Similarly, water wheel animation is also a looping animation created for rotating water wheel paddles. This animation is played when the environment is rainy, and when the player places the water wheel on the river after buying it from the tools inventory.

Finally, the animation of the river is created for realistically animating river waves. This animation is created by altering the shader wave speed property. This property is represented as a vector of four components $(x, y, z, w)$ controlling the river tiles' speed. This property can have two different values that are determined by the environmental mood. It is set to $(-8,7,6,8)$ to create the appearance of a fast-moving river for the rainy mood. Meanwhile, it is set to $(-2,2,1,3)$ for other environmental modes to create a slow wave animation.

\subsection{DAYSAM's Particles}

Most game elements are represented by 3D game objects with specific materials and textures, occasionally extended with animations. For motion graphics, the Unity particle system is used to create particle graphics.

Rain particles are rendered in the rainy environment, emitting sphere rain drop particles. The lifetime for the particles is set to a random value between 2.5 and 3 . When emitted, the initial speed for the rain particles is set to a random number between 15 and 25 . The rain drops are set randomly to a color between white color with an opacity of $0 \%$ and white color with an opacity of $67 \%$. After all, 500 particles are emitted by a unit of time. Figure 8 shows a screenshot of the rain emitting from the clouds.

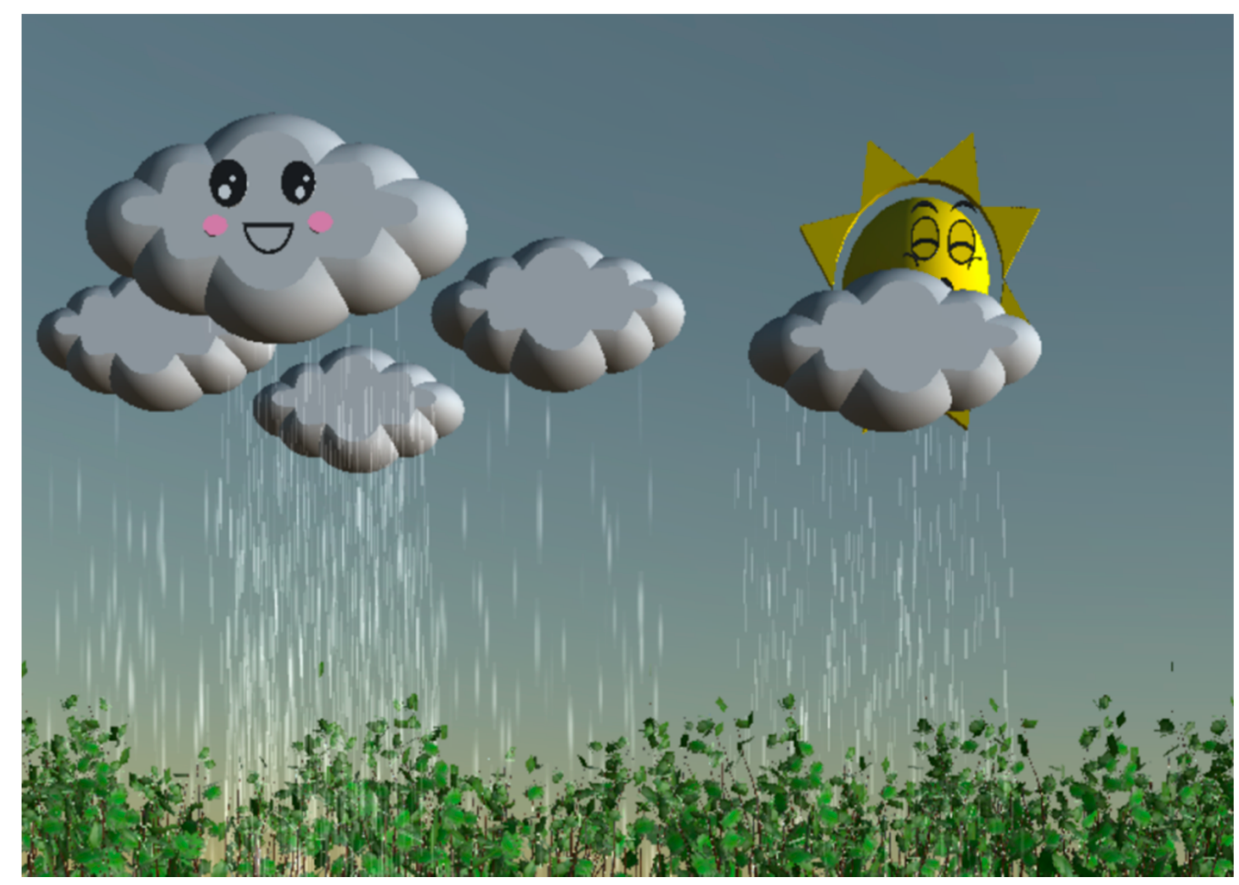

Figure 8. Rain particles. 
Smoke particles are configured as a looping particle effect rendered in all game environment moods. The smoke particles' lifetime is controlled by the initial number of lit rooms and the user actions. An initial value of 15 is given as lifetime for the smoke. Here, every lit room adds 2.5 to this value, while the max number that can be reached is 30 . If the user turns off a room light, the lifetime value decreases by 2.5. When all of the room's lights are off, the smoke lifetime goes back to its initial value (15). Meanwhile, if the user buys the right tool and places it in the right place, the particle system stops emitting smoke particles setting the lifetime of the particles to zero. To create a cloud of realistic smoke, size over lifetime is enabled, which allows the smoke size to change its size over time. The initial speed for the smoke particles is set to 11 . The shape of the emission volume is a cone with an angle of 17.5 and a radius of 1 . In order to create the effect of smoke fading out over time, color over time has been enabled. This function allows changing the transparency of the smoke particle over its lifetime from $100 \%$ to $0 \%$.

The coins particles are emitted for $0.5 \mathrm{~s}$ every time the player turns off a room light. Particle commencement speed is a random number between 10 and 15 . The emission shape is a cone with an angle of 22 and a radius of 1 .

Finally, the confetti particles have a lifetime value of 15 and a start speed of 30, and a start size of 2 . The particles' first color sets a gradient of eight color values to have the particles emitted in different colors. A particle system provides an ability to use physics gravity. It can be achieved by using the particle system's gravity modifier property. The confetti particle gravity modifier is set to a value of 5 , while 70 confetti particles are emitted per second.

As for game lighting, mixed lighting with baked global illumination enabled techniques are used in the game. In addition to that, a baked indirect lighting mode is applied. This provides real-time direct lighting while indirect lights are baked into light maps and light props. The main light for the game is a directional light using mixed lighting. This light rotates around the $y$-axis and is dynamically changed every time the game starts. For the sunny environment, the y rotation value is equal to 120 degrees creating an early morning scene. For other environments, the y rotation value is set to 180 , creating an afternoon scene.

Since we want to address potential users with mobile phones of limited memory, processing, and graphical capabilities, game performance is crucial in the development process. Thus, different approaches are taken to address this issue. First, all game models are designed with a minimum number of triangles and vertices. Second, non-moving objects are set to static using baked lighting. With this practice, only baked lighting precomputation is used. For development and validation, Unity frame debugger and profiler have been used to test the game performance.

Figure 9 shows a capture of the developed DAYSAM. This is a winning scene with a photovoltaic array installed to replace the diesel generator's power as the environment is sunny. Moreover, the polar bear is happy as this action rescues him. The smoke emitted from the diesel generator has stopped. 


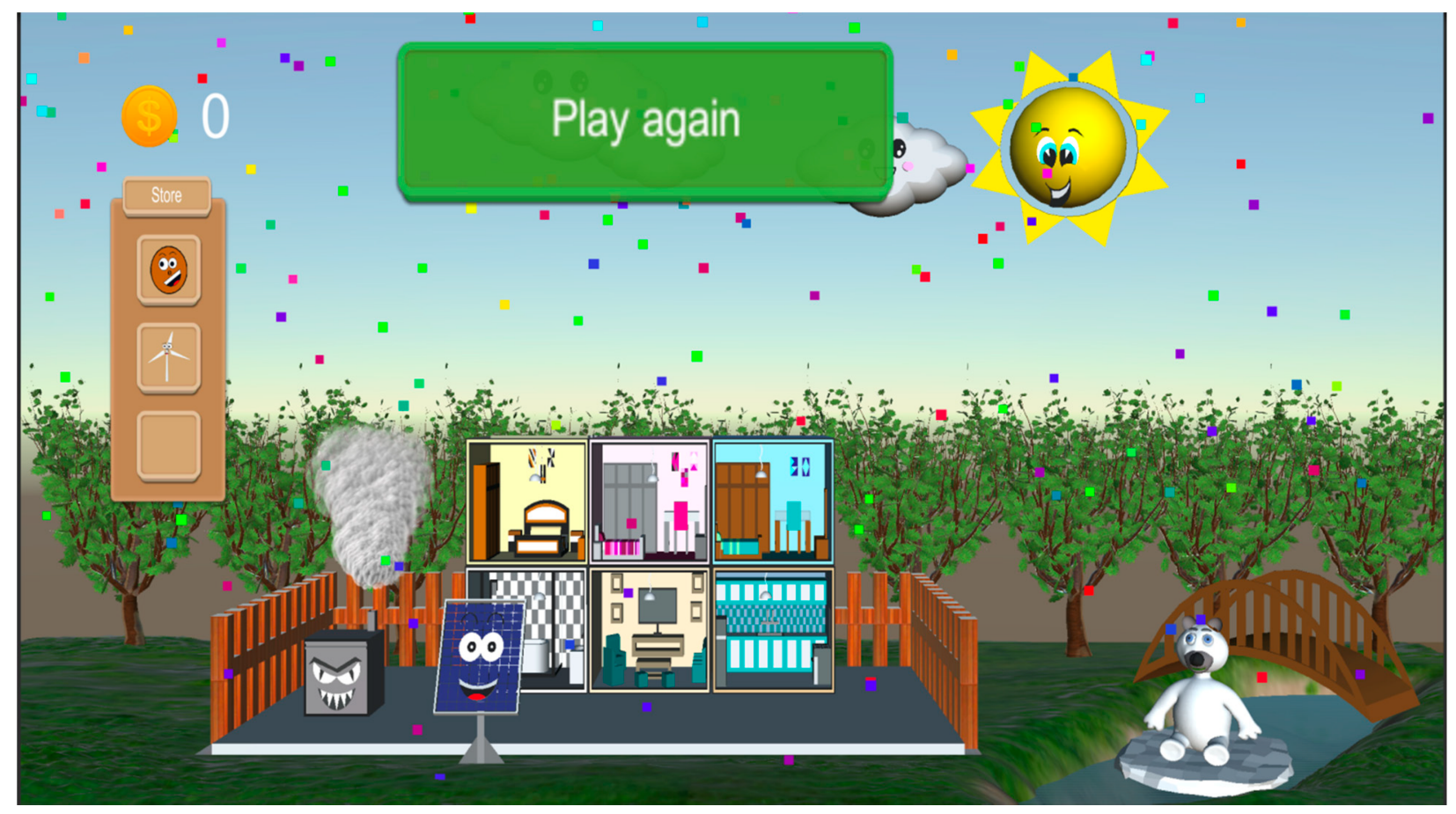

Figure 9. A screen shot of DAYSAM.

\section{Testing Methods}

In this research, two main testing methods are applied; pilot testing method and main testing method which is named afterwards as testing campaign.

In the pilot testing method, the testing is done based on the coloring sheets showed previously in Figures 1 and 2. The developed game has been installed in five convenient tablets and distributed to five preschoolers from An-Najah Child Institute's nursery. This sample is considered representative with an acceptable confidence level (95\%) and marginal error $(27 \%)$ as it is almost $12.5 \%$ of the total preschoolers in the nursery. However, the confidence level and the marginal error might be more indicative in the case of regular questionnaires such as the (yes or no) questionnaires or the Likert scale questionnaires. However, in our case, a different surveying methodology is applied where the children are asked to color sheets, whereas the marginal error, for example, is challenging to be determined. Thus, applying a qualitative approach here might be more reasonable. In the following, the results from pre- and post-testing are reported.

On the other hand, in the testing campaign, the testing is done based on the coloring sheets illustrated in Figure 3. A national call in Palestine was made to about 170 kindergartens to participate in the testing campaign in a follow-up process. Following that, 47 kindergartens agreed to participate in the testing campaign. These kindergartens are distributed all over Palestine and represent the Palestinian preschoolers.

A randomized control trial process was applied to test this app by implementing the test to two groups: a test group and an untreated control group. A total of 24 kindergartens were asked to dedicate one hour after lunch (12:30-13:30) to telling the preschoolers about the environment and renewable energy and then allow them to play the game for $30 \mathrm{~min}$ by using DAYSAM. Meanwhile, 23 kindergartens were asked to dedicate the same hour to telling the preschoolers about environment and renewable energy, whereas they can use illustrating pictures and figures without using DAYSAM. This process was repeated three times a week for four months (10th of January to 5th of March, face to face education, and from 5th of April to 26th May, (e-learning due to COVID-19). During this process, 854 preschoolers have participated in the campaign. This sample is supposed to represent a 
significant part of the population of preschoolers in Palestine, which is 91,661 with margin of error of $3.5 \%$ and confidence of $95 \%$.

\section{Results}

\subsection{Pre-Testing Results}

For the pre-testing, the preschoolers were asked to color the coloring sheet shown in Figure 1 three times for two weeks. The pre-testing was done for an hour (from 14:30-15:30), after lunch in a calm hall. Coloring was not supervised by a teacher or persons conducting the study. Figure 10 shows the pre-testing results.

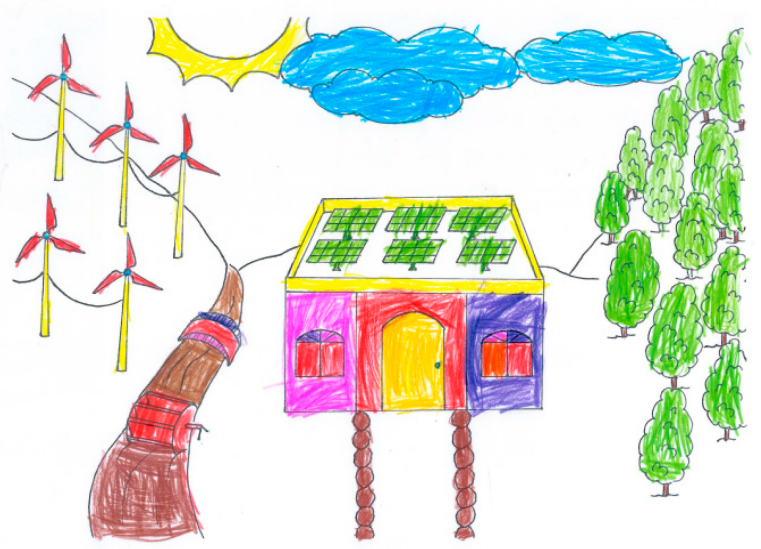

Ebaa A

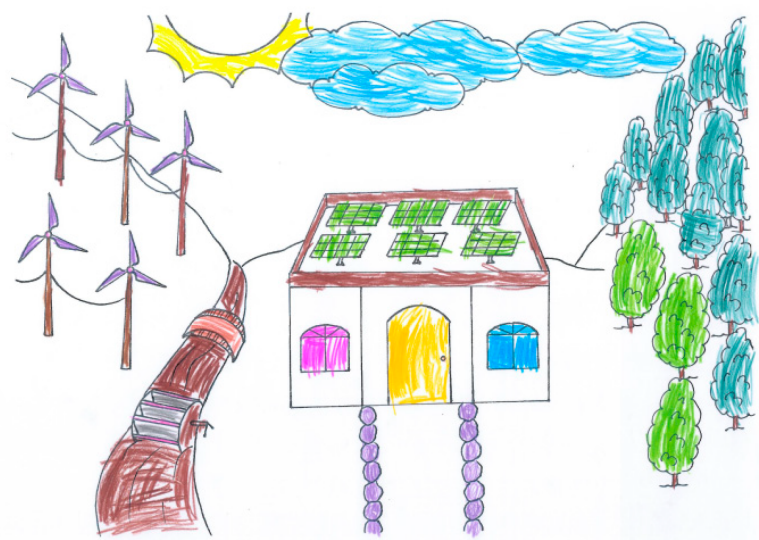

Roza A

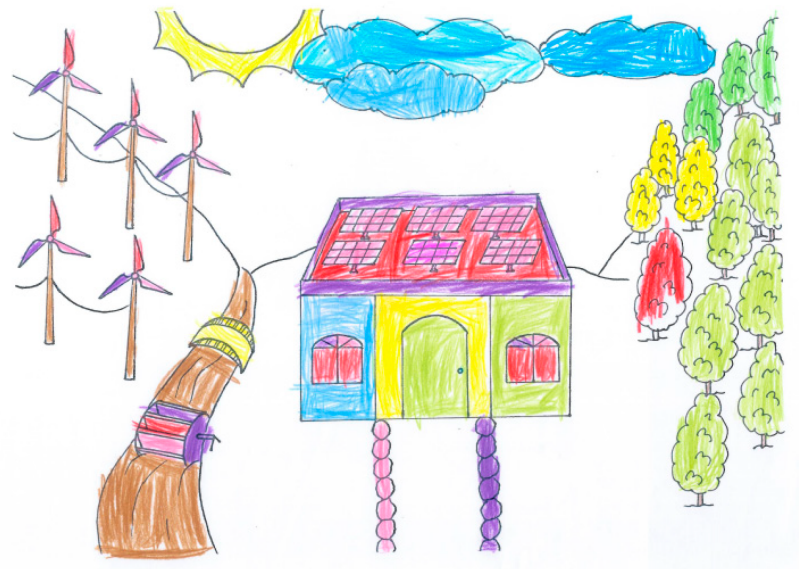

Ebaa B

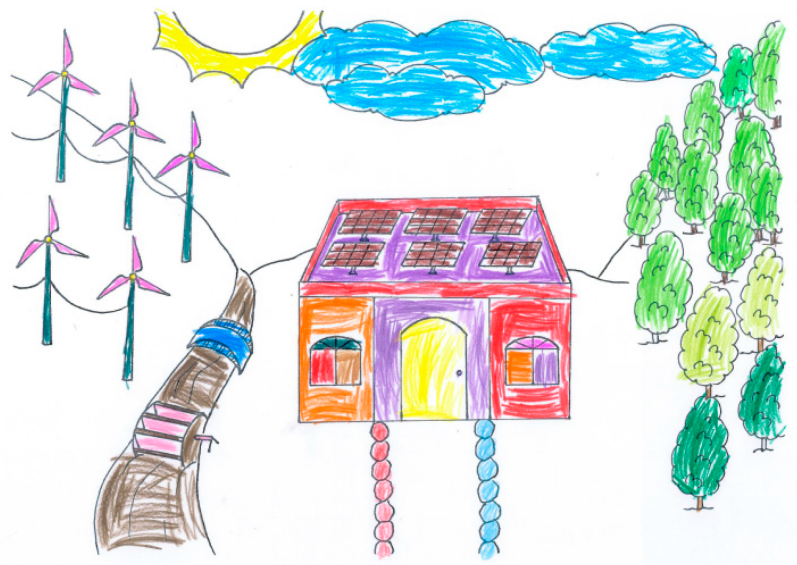

Roza B

Figure 10. Cont. 


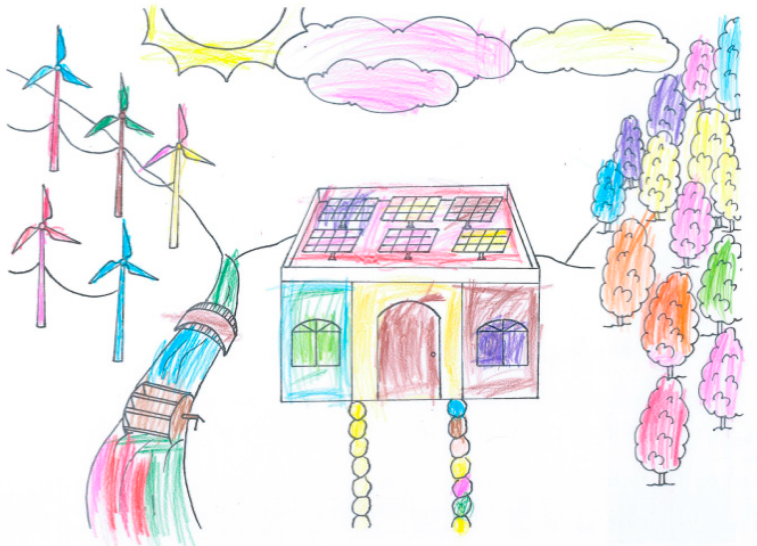

Rayna A

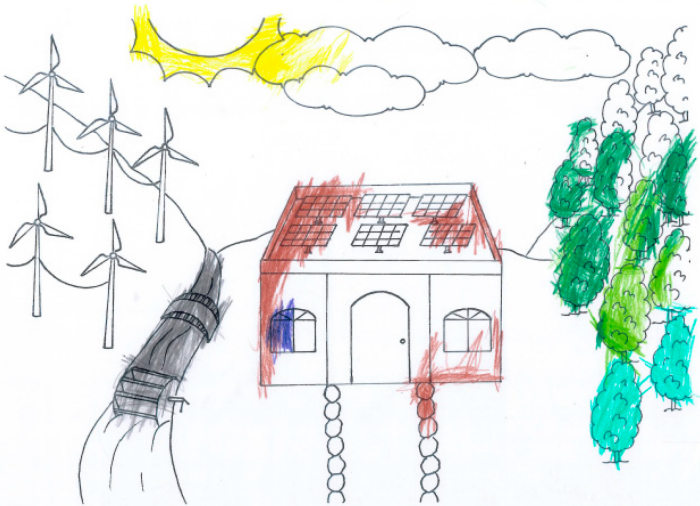

Karam A

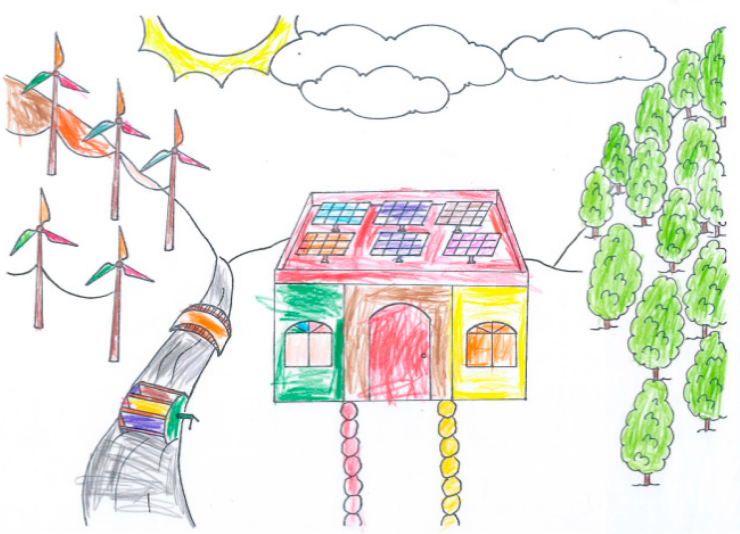

Ghaith A

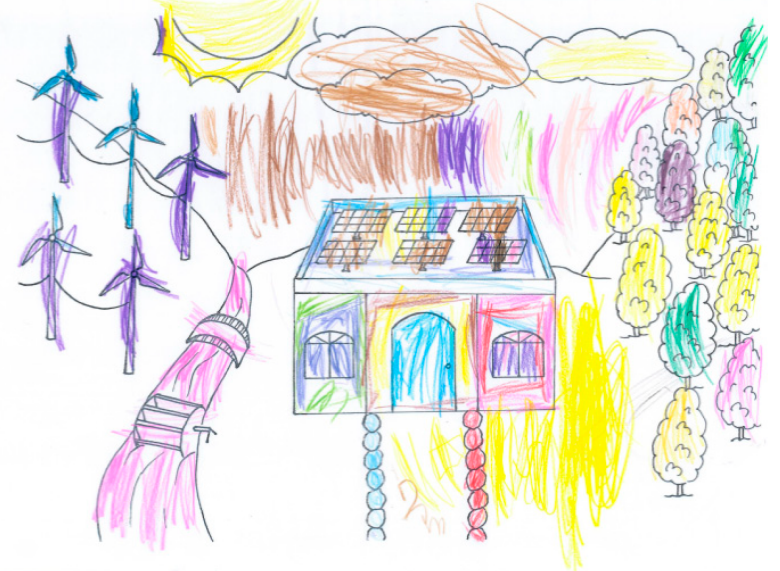

Rayna B

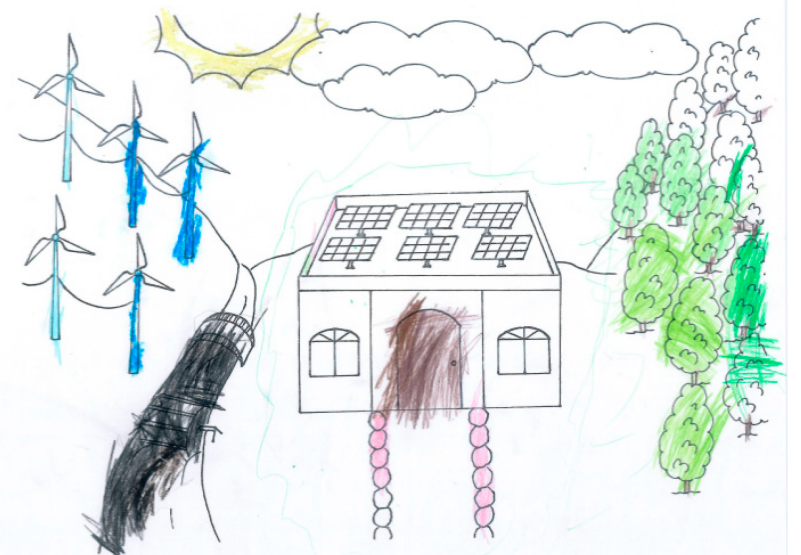

Karam B

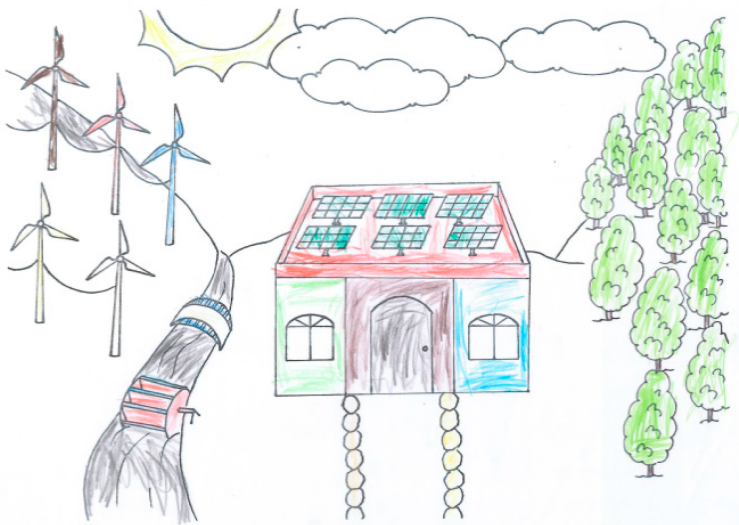

Ghaith B

Figure 10. Pre-testing results from the selected preschoolers.

The pre-testing was done on five preschoolers Ebaa (Female, five years), Roza (Female, five years), Rayna (female, five years), Karam (male, four years), and Gaith (male, six years). From the figure, $80 \%$ of the preschoolers have recognized (i.e., colored in green) the trees (all except Rayna), while $100 \%$ of them have recognized (i.e., colored in yellow) the sun. Overall, $40 \%$ of them have colored the clouds as blue as sky (Ebaa and Roza), while $40 \%$ of them have left the clouds white (Karam and Ghaith). In total, $20 \%$ of them gave the clouds a less common color (Rayna). The river was never painted blue, indicating that the river 
was not recognized as such. This might be due to the nature of Palestine, where very few rivers exist. To represent renewable energy sources, there are several PV panels and wind turbines on the pre-testing sheet.

Figure 9 indicates that none of the preschoolers recognized the photovoltaic arrays even though $80 \%$ of them have recognized these parts as different parts from the roof (colored in different colors from the roof). Coloring of the wind turbines yields a similar result, which are colored in uncommon ways. However, it is interesting to mention that $80 \%$ of the preschoolers (all except Karam) have differentiated between the wind blades and the mounting tower. Overall, the pre-test results indicate that the preschoolers do not recognize any of the renewable energy sources. Based on results from all coloring sheets, we assume a low awareness of renewable energy generating sources.

\subsection{Pilot Test Results}

In order to evaluate the impact of the of developed game, the preschoolers were given a slightly modified coloring sheet (shown in Figure 2) sometime after playing the game. They were asked to color it three times during two weeks after playing the game for one month (see Figure 11).

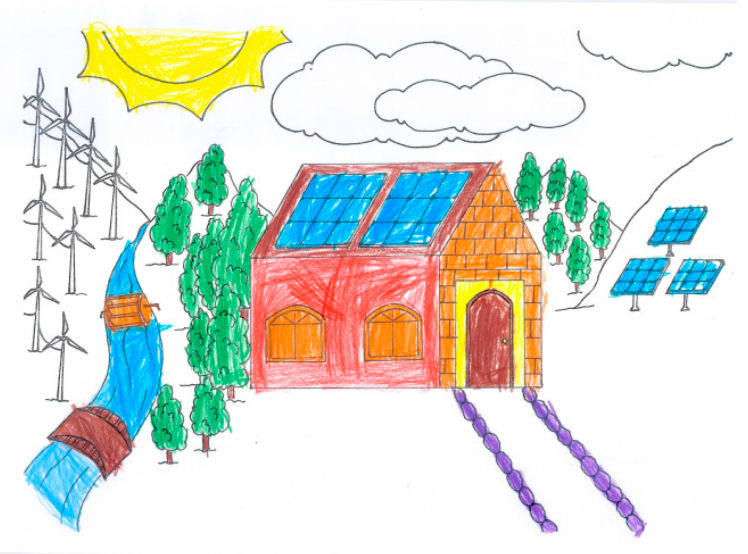

Ebaa A

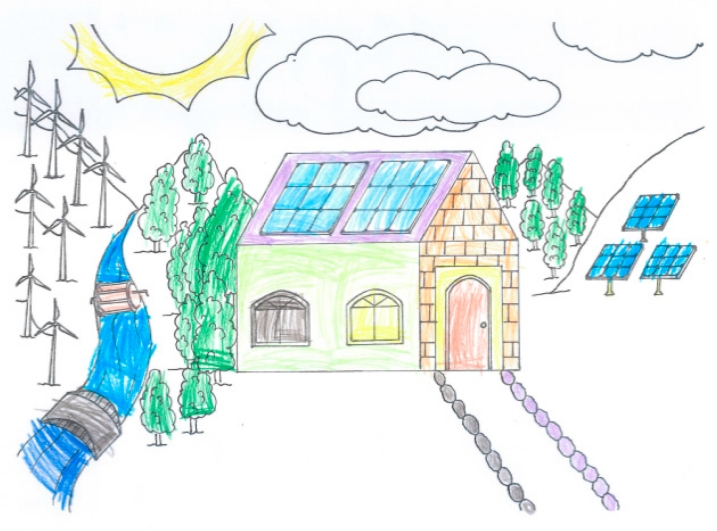

Roza A

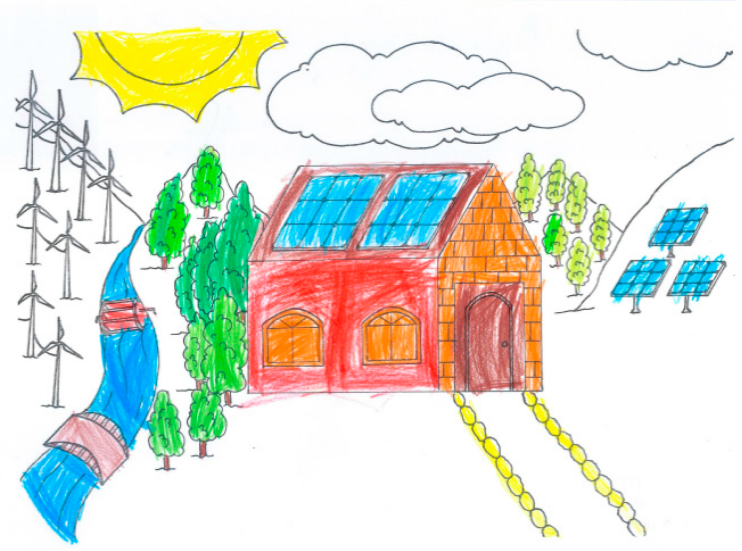

Ebaa B

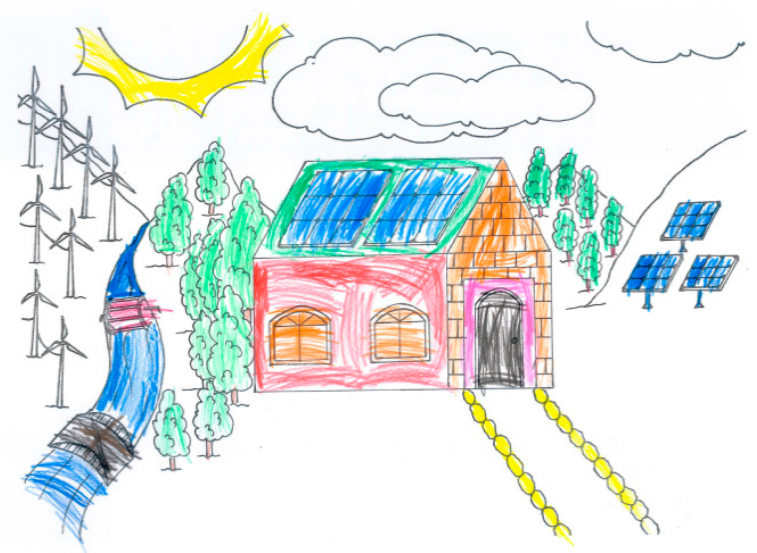

Roza B

Figure 11. Cont. 


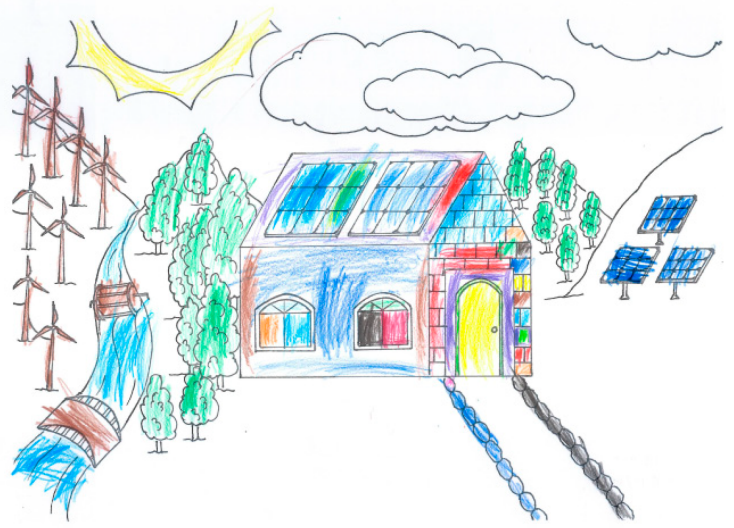

Rayna A

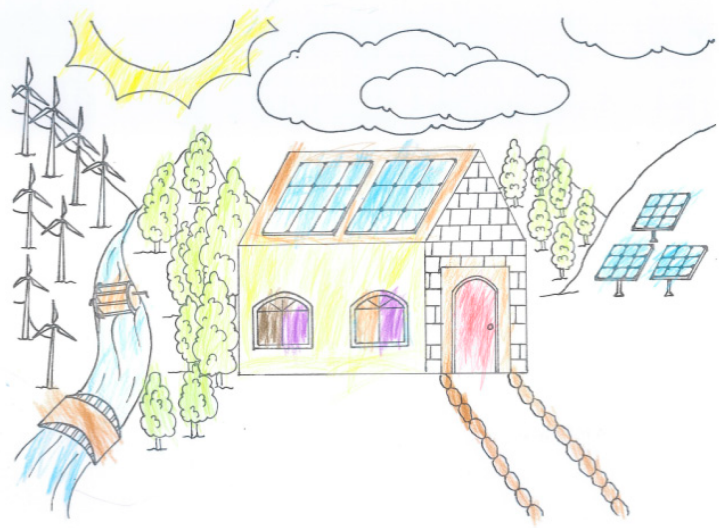

Karam A

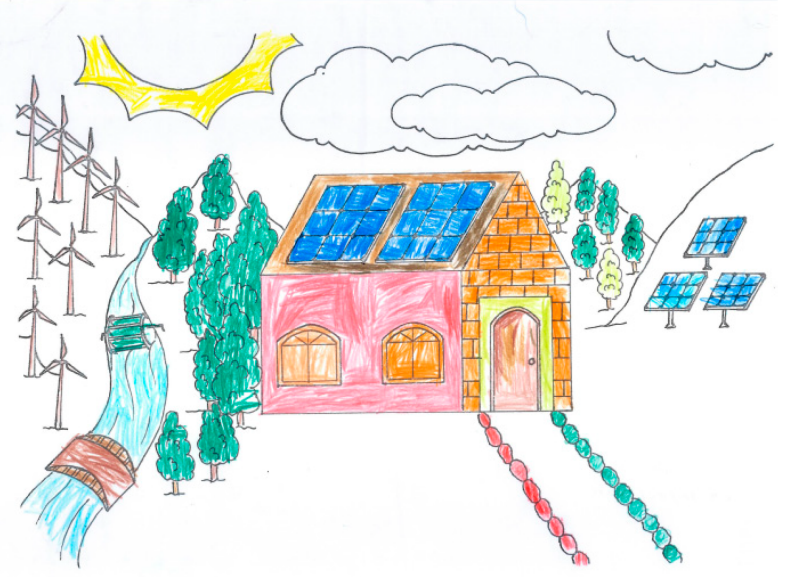

Ghaith A

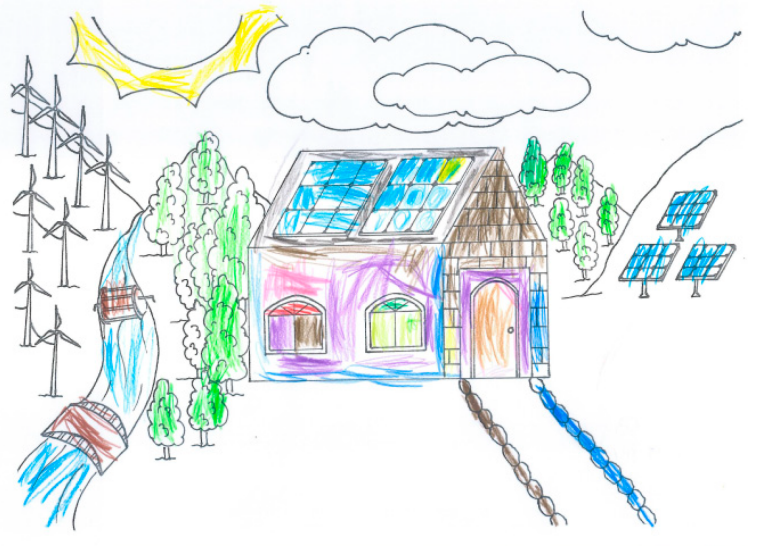

Rayna B

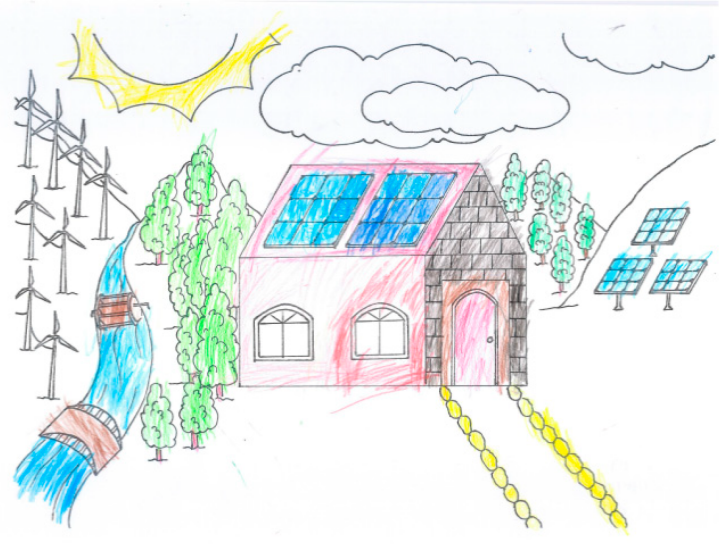

Karam B

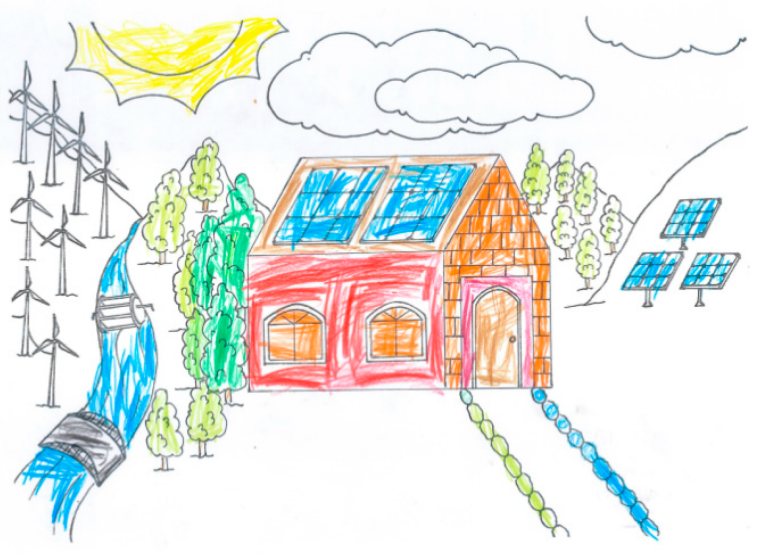

Ghaith B

Figure 11. Testing results of the selected preschoolers after playing DAYSAM.

From the figure, all preschoolers have recognized trees and clouds. These elements, in fact, appear in the game with green color for trees and white color for clouds. In this phase, we have added two types of photovoltaic arrays; one is the rooftop while the other is ground-mounted. This is to check if the students recognize the photovoltaic array as an individual element or based on the whole scene color. All preschoolers have recognized the photovoltaic array as a different part from the roof and color blue as it should be, although in the game, the utilized PV array is ground-mounted not a roof top element. This is to 
say that the preschoolers have recognized the element as a photovoltaic array based on its graphical features, not place.

We noticed similar results for the river and the hydraulic wheel, whereas all of the preschoolers have followed the colors that appeared in the game scene.

As for the wind turbine, all of the preschoolers have left blank the part to indicate a while color for these devices, except one case where brown color was used for some of the wind turbines. Overall, this indicates that the game has improved the awareness of the preschoolers of renewable energy sources.

\subsection{Testing Campaign Results}

After getting positive results from the initial pilot, the game was published as a smartphone app at Apple store as "DAYSAM" as shown in Figure 12.

\section{Search}

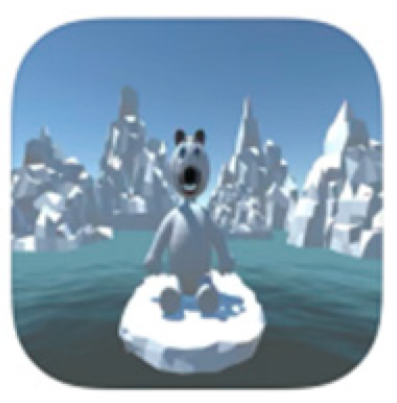

\section{Daysam}

\section{Tamer Khatib}

\section{GET}
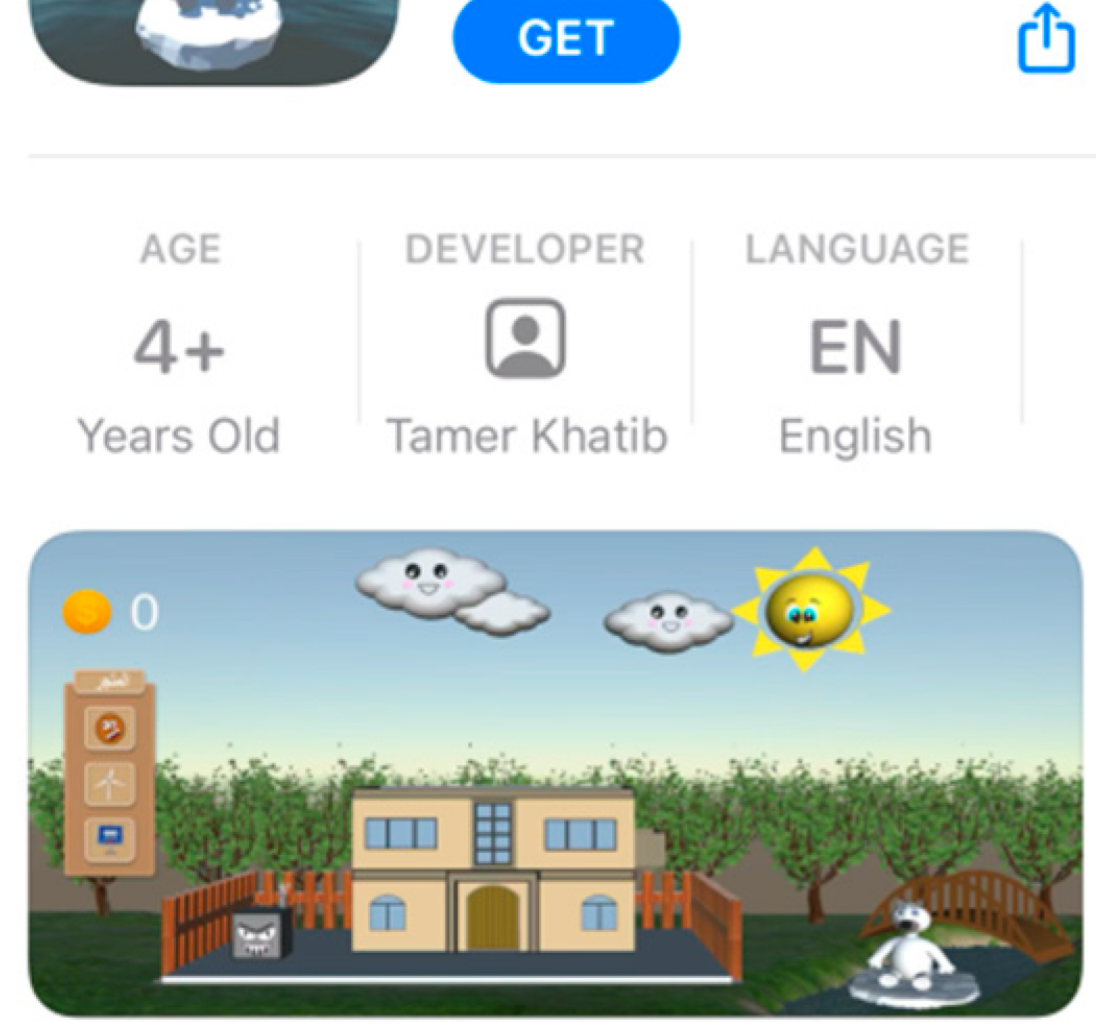

Figure 12. Capture of App store search results for DAYSAM.

The testing campaign is done based on responses from 854 preschoolers (estimated total number of preschoolers in Palestine is 91,661) from 47 different kindergartens in Palestine. These kindergartens are distributed all over Palestine and represent the Palestinian preschoolers. The age of the selected preschoolers is in the range of (3-5 years), whereas $31 \%$ of them are three years old, $49 \%$ of them are four years old and $20 \%$ of them are 
five years old. In this campaign, $61 \%$ of the selected respondents are females. This percentage is associated with the average gender demography in the selected Kindergartens. The selection of the respondents was done is association with kindergartens' teachers, whereas we have asked them to select different types of preschoolers based on their performance in the class. The performance of preschoolers in the class was judged mainly based on average response ability, visual ability, processing ability and memory ability. Thus, kindergartens' teachers were asked to select a sample of respondents based on their class experience, in way that the sample contains, $10-20 \%$ of the preschoolers who are the best in the aforementioned four abilities, $10-20 \%$ of the preschoolers who are the least among their colleagues considering the aforementioned abilities, while those remaining should represent the average of the class. Here we could not judge the exact percentages of the selected preschoolers considering the aforementioned abilities as it is not our role to judge the general performance of the preschoolers, while we just trusted the choice of the kindergartens' teachers.

A randomized control trial process was applied to test this app by implementing the test to two groups: a test group ( $51 \%$ of the selected preschoolers) and an untreated control group ( $49 \%$ of the selected preschoolers). For the test group, 24 kindergartens were asked to dedicate one hour after lunch (12:30-13:30) to tell the preschoolers about the environment and renewable energy and then allow them to play the game for $30 \mathrm{~min}$ by using DAYSAM. Meanwhile, as for the untreated control group, 23 kindergartens were asked to dedicate the same hour to tell the preschoolers about environment and renewable energy, whereas they could use illustrating pictures and figures without using DAYSAM. This process was repeated three times a week for four months (10th of January to 5th of March, face to face education, while from 5th of April to 26th May, (e-learning due to COVID-19). This sample is supposed to represent a significant part of the population of preschoolers in Palestine, with margin of error of $3.5 \%$ and confidence of $95 \%$.

Table 2 shows a sample of the results of the untreated control group. Accordingly, Table 3 shows a sample of the results of the test group.

After collecting all samples, an analysis is conducted to these coloring sheets. The analysis was aimed at answering the research questions by Yes or No. The answer was based on the color used in the coloring sheet. Table 4 summarizes the results of the conducted testing campaign 
Table 2. Sample of the results of the untreated control group.

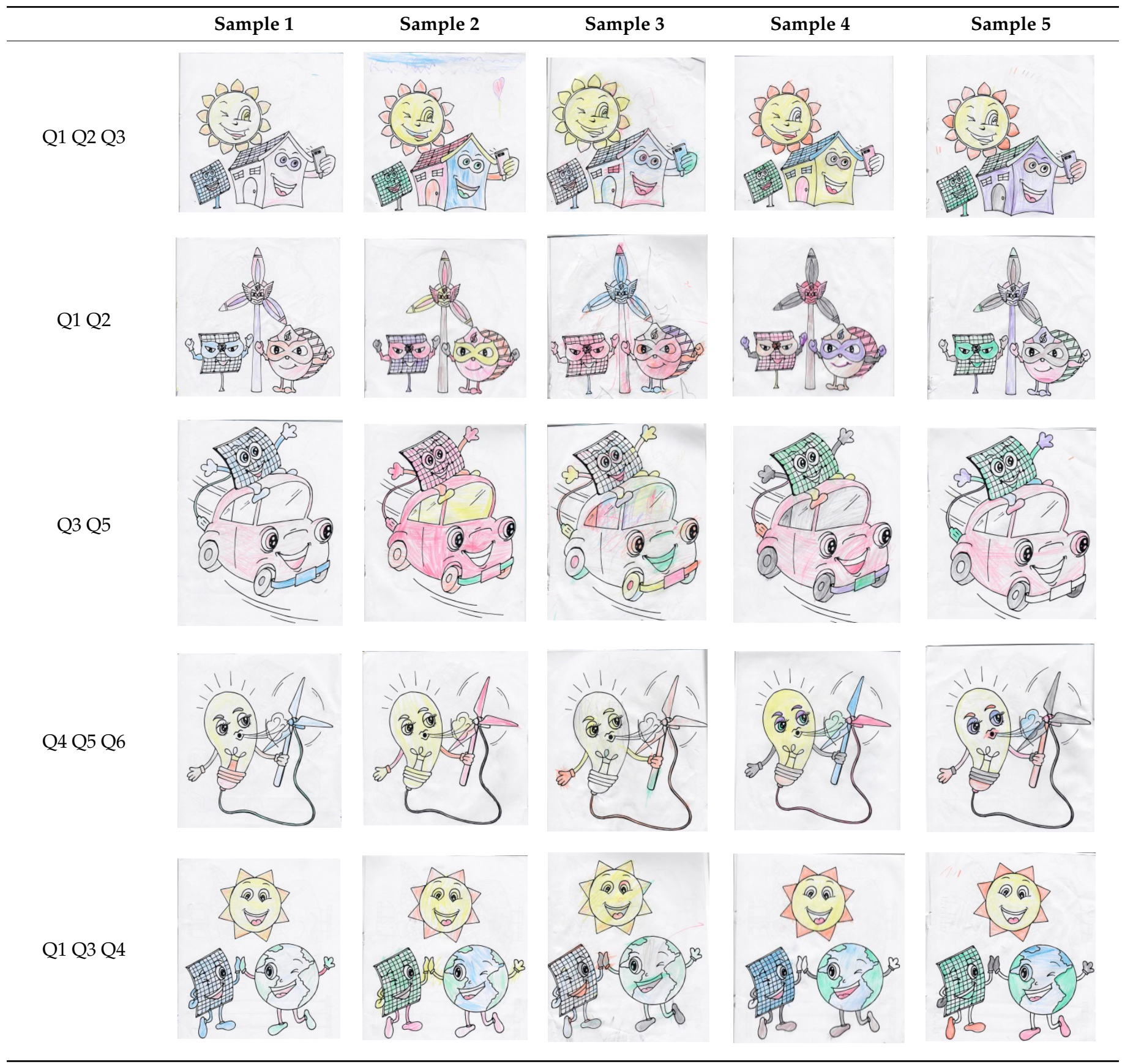


Table 3. Sample of the results of the test group.

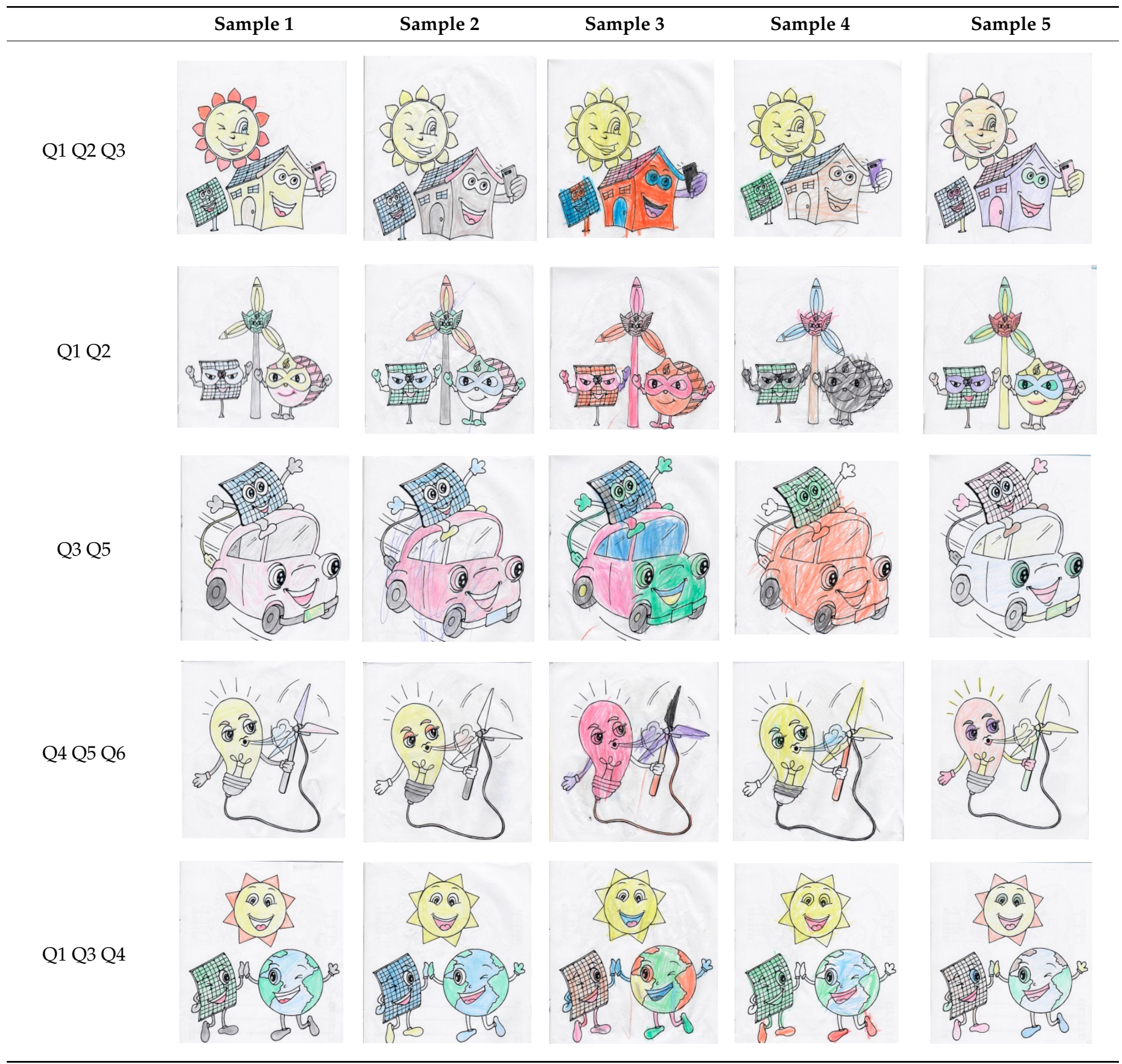

Table 4. Results of the testing campaign.

\begin{tabular}{ccccc}
\hline & \multicolumn{2}{c}{ Untreated Group (49\%) } & \multicolumn{2}{c}{ Test Group (51\%) } \\
& Male (41.7\%) & Female (58.3\%) & Male (38.8\%) & Female (62.2\%) \\
\hline Recognition of solar cell (standalone) & $22.5 \%$ & $33.4 \%$ & $27.6 \%$ & $57.1 \%$ \\
Recognition of roof top solar cell & $21.3 \%$ & $20.4 \%$ & $31.6 \%$ & $52.3 \%$ \\
Recognition of sun & $98.3 \%$ & $98.6 \%$ & $97.2 \%$ & $98.7 \%$ \\
Recognition of earth & $98.6 \%$ & $98.2 \%$ & $92.1 \%$ & $93.4 \%$ \\
Recognition of wind turbine & $13 \%$ & $15 \%$ & $21.3 \%$ & $33.1 \%$ \\
Recognition of lighting lamp & $73 \%$ & $75 \%$ & $88 \%$ & $94 \%$ \\
\hline
\end{tabular}


From these results, most of the preschoolers know about Sun and Earth, whereas the results were close for both groups. About $98.4 \%$ of the preschoolers in the untreated group successfully recognized the Sun and Earth, while $92.8 \%$ of the preschoolers in the test group also successfully recognized the Sun and earth. Here, it is evident that the proposed application did not improve the preschoolers' knowledge in this regard. On the contrary, it is noted that the average of the untreated groups is slightly better than the test group. This might be due to a natural difference in the characteristic of the two groups. It is also might be because of the focus given in both groups. In the untreated groups, the teachers were asked to use illustrations and posters to tell them about the renewable energy environment. In contrast, in the test group, the preschools used the app as a learning tool. Here, the utilized posters and illustrations might contain more icons of the Sun and Earth.

As for the first research questions, the preschools recognized the standalone solar cell in the untreated group with an average of $28 \%$, and an average of $42.35 \%$ in the test group. This indicates that the recognition of a standalone solar panel is low in both cases. However, using the proposed application has made some difference. Another interesting observation is that females recognized the solar cell significantly better than males in both cases. In the test group the females have recognized the solar cell by about $200 \%$ more males. This difference might be due to different interest in playing an educational game between genders. As for the recognition of the standalone solar cell, $20.9 \%$ of the preschooler in the untreated group recognized the standalone solar cell while $42 \%$ of preschoolers recognized in the test group. Here, females exceeded males in recognizing the object and consequently increasing the recognition average in the test group. However, it is also evident that the preschoolers in the test group performed better.

On the other hand, low recognition averages were noticed for the wind turbine, whereas only $14 \%$ of the preschoolers recognized it. This average was found better in the test group, where it was $27.2 \%$.

Finally, preschoolers in the untreated group recognized the lighting lamp correctly with an average of $74 \%$. In comparison, this also was better in the test group, where the average was $91 \%$.

Based on these results, we believe that the main hypothesis of this research is validated by answering the previous research questions, whereas it is clear that the proposed application has helped preschoolers in recognizing renewable energy features better than those who did not use the proposed application. However, it is also noted that the application does not have that huge impact on the preschoolers due to some limitations which are discussed in the following section. These limitations should be considered in developing the proposed application as future work.

\section{Conclusions and Future Work}

In this research, a smartphone application game has been developed to increase preschoolers' renewable energy awareness in the age of 3-6 years. Unlike comparable studies, the game's interface is in Arabic language. The game called DAYSAM aims to increase awareness regarding photovoltaic arrays, wind turbines, mini-hydropower stations, energy efficiency, and risks that polar bears are facing. For a pilot study, preschoolers from An-Najah Child Institute were selected. These preschoolers' awareness was tested before and after playing the game in an unsupervised process using a coloring sheet. Results indicate that the proposed game has increased the preschoolers' awareness and that the coloring sheet can be used as a means to evaluate the familiarity with an object.

In a follow-up test campaign, the approach has been evaluated with a significant number of participants, separated into an untreated control group and a test group that was shown the developed game. Results indicated that the test group showed a better ability to recognize renewable energy objects on a color sheet in most cases. Female participants typically exceeded in both groups.

In general, the following conclusions can be drawn after analyzing the testing sheets: 
- In most cases, the test group showed better performance than the untreated group.

- The females exceeded males in all cases in both test and untreated groups. This may exaggerate the improvement rate when comparing the test and untreated groups.

- The proposed application did not affect the recognition of the Sun and Earth, while it slightly improved the recognition of the lighting lamp.

- The proposed application slightly improved the recognition of standalone, rooftop solar cells and wind turbines for male participants. For female participants, the improvement was more significant than with male participants.

- In general, the preschoolers' initial awareness of renewable energy leaves room for improvement and makes a case for the proposed tool.

In addition, conducting this testing campaign has brought attention to some important aspects to be considered when developing education (computer) games:

- Game environment and methodology should always be close to trending games to attract players more

- Quality of graphics plays a very important role in attracting players to educational games

- It might be better to develop special educational games for males and females considering their respective trending games

While these results encourage the usage of a mobile computer game for increasing awareness, it was noticed that preschoolers were easily bored from playing the game since the game has just one (variable) level. The game's future development will contain more scenes with different graphical designs, more homes with more difficult energy efficiency procedures, and more renewable energy sources. We foresee that such a game can be used as a fun and educational tool in nurseries with Arabic as the communication language.

Author Contributions: Conceptualization, T.K. and A.A.; methodology, H.A., W.M., T.K., W.E., M.Z., and A.A.; software, H.A., Y.A.-G. and W.M.; validation, T.K., F.A.-G. and M.Z.; formal analysis, T.K.; investigation, T.K.; writing—original draft preparation, H.A., W.M., T.K., W.E., M.Z., and A.A.; software, H.A., Y.A.-G. and W.M.; writing-review and editing, T.K.; supervision, T.K.; project administration, A.A. All authors have read and agreed to the published version of the manuscript.

Funding: This research is funded by Palestine Ministry of Education and Higher Education and An-Najah National University grant number ANNU-MoHE-1819-So005.

Institutional Review Board Statement: Not applicable.

Informed Consent Statement: Informed consent was obtained from all subjects involved in the study.

Data Availability Statement: Data are available with authors upon request.

Conflicts of Interest: The authors declare no conflict of interest.

\section{References}

1. Yaqoot, M.; Diwan, P.; Kandpal, T.C. Review of Barriers to the Dissemination of Decentralized Renewable Energy Systemscable and Sustainable Energy Reviews; Elsevier Ltd.: Amsterdam, The Netherlands, 2016; Volume 58, pp. 477-490. [CrossRef]

2. Assali, A.; Khaitb, T.; Najjar, A. Renewable energy awareness among future generation of Palestine. Renew. Energy 2019, 139, 254-263. [CrossRef]

3. Phongthanachote, C.; Rattanadecho, P.; Prommas, R. Animation and Computer Games Design to Build Awareness of Energy Conservation Chern Com-arch. Sci. Technol. Asia 2019, 21-29. [CrossRef]

4. Runyan, J.D.; Steenbergh, T.A.; Bainbridge, C.; Daugherty, D.A.; Oke, L.; Fry, B.N. A Smartphone Ecological Momentary Assessment/Intervention "App" for Collecting Real-Time Data and Promoting Self-Awareness. PLoS ONE 2013, 8, e71325. [CrossRef] [PubMed]

5. Mayer, R.E. Computer games in education. Annu. Rev. Psychol. 2019, 70, 531-549. [CrossRef] [PubMed]

6. Gee, J. What Video Games Have to Teach Us about Learning and Literacy; Palgrave Macmilla: New York, NY, USA, 2003.

7. McGonical, J. Reality Is Broken: How Games Make Us Better and They Can Change the World; Penguin Press: New York, NJ, USA, 2011.

8. Prensky, M. Don't Bother Me Mom: I'm Learning; Paragon Press: St. Paul, MN, USA, 2006.

9. Schafer, D.W. How Computer Games Help Children Learn; Palgrave Macmillan: New York, NY, USA, 2006.

10. Squire, K. Video Games and Learning; Teachers College Press: New York, NY, USA, 2011.

11. Game-Based Platform Energy-Efficient Virtual Cities. Intelligent Energy Europe. Available online: https://ec.europa.eu/energy/ intelligent/projects/en/projects/enercities (accessed on 18 December 2020). 
12. Ollie's World-Interactive Sustainability Resource for Kids. Available online: https://www.olliesworld.com/ (accessed on 18 December 2020).

13. Nico's Activities for Kids. Available online: https://www.saveonenergy.com/kids-learning-center/ (accessed on 18 December 2020).

14. WindFall. Available online: https://games4sustainability.org/gamepedia/windfall/ (accessed on 18 December 2020).

15. Chun, S.G.; Chung, D.; Shin, Y.B. Are Students Satisfied with the use of Smartphone Apps? Issues Inf. Syst. 2013, 14, 23-33. [CrossRef]

16. Garber, L.L.; Burke, R.R., Jr.; Jona, M.J. The Role of Package Color in Consumer Purchase Consideration and Choice; Marketing Science Institute: Cambridge, MA, USA, 2000; p. 1-46.

17. Sobe, A.; Elmenreich, W. Smart microgrids: Overview and outlook. In Proceedings of the ITG INFORMATIK Workshop on Smart Grids, Braunschweig, Germany, 16-21 September 2012. 